\title{
Agriculture Data Analytics in Crop Yield Estimation: A Critical Review
}

\author{
B M Sagar, Cauvery N K \\ Department of Information Science \& Engg, R V College of Engineering, Bengaluru, Karnataka, India
}

\begin{tabular}{l}
\hline \hline Article Info \\
\hline Article history: \\
Received May 2, 2018 \\
Revised Jun 15, 2018 \\
Accepted Sep 25, 2018 \\
\hline
\end{tabular}

\section{Keywords:}

Agriculture data

Crop yield

Data analytics

Prediction

Smart farming

\begin{abstract}
ABSTCT
Agriculture is important for human survival because it serves the basic need. A well-known fact that the majority of population $(\geq 55 \%)$ in India is into agriculture. Due to variations in climatic conditions, there exist bottlenecks for increasing the crop production in India. It has become challenging task to achieve desired targets in Agri based crop yield. Various factors are to be considered which have direct impact on the production, productivity of the crops. Crop yield prediction is one of the important factors in agriculture practices. Farmers need information regarding crop yield before sowing seeds in their fields to achieve enhanced crop yield. The use of technology in agriculture has increased in recent year and data analytics is one such trend that has penetrated into the agriculture field. The main challenge in using big data in agriculture is identification of effectiveness of big data analytics. Efforts are going on to understand how big data analytics can agriculture productivity. The present study gives insights on various data analytics methods applied to crop yield prediction and also signifies the important lacunae points' in the proposed area of research.
\end{abstract}

Copyright $@ 2018$ Institute of Advanced Engineering and Science. All rights reserved.

\section{Corresponding Author:}

B M Sagar,

Department of Information Science \& Engg,

R V College of Engineering,

Bengaluru, Karnataka, India.

Email: sagarbm@rvce.edu.In

\section{INTRODUCTION}

Agriculture forms the basis for food security and hence it is important. In India, majority of the population i.e., above $55 \%$ is dependent on agriculture as per the recent information. Agriculture is the field that enables the farmers to grow ideal crops in accordance with the environmental balance. In India, wheat and rice are the major grown crops along with sugarcane, potatoes, oil seeds etc. Farmers also grow non-food items like rubber, cotton, jute etc. More than $70 \%$ of the household in the rural area depend on agriculture. This domain provides employment to more than $60 \%$ of the total population and has a contribution to GDP also (about 17\%) [1]. In the farm output, India ranks second considering the world wide scenario. This is the widest economic sector and has an important role regarding the framework of socio-economic fabric of India. Farming depends on various factors like climate and economic factors like temperature, irrigation, cultivation, soil, rain fall, pesticide and fertilizers. Historical information regarding crop yield provides major input for companies engaged in this domain. These companies make use of agriculture products as raw materials, animal feed, paper production and so on. The estimation of production of crop helps these companies in planning supply chain decision like production scheduling. The industries such as fertilizers, seed, agrochemicals and agricultural machinery plan production and activities like marketing based on the estimates of crop yield [2]. Farmers experience was the only way for prediction of crop yield in the past days. Technology penetration into agriculture field has led to automation of the activities like yield estimation, crop health monitoring etc. Crop yield prediction has generated a lot interest in the research community and also 
for agriculture related organizations. Crop yield prediction helps the farmers in various ways by providing the record of previous crop yield. This is helpful to government in framing policies related to crops such as crop insurance policies, supply chain operation policies. Knowing what crops has been grown, and how much area of it had been shown historically, combined with the prices at which it could have been sold at the nearest market-place provides the income-growth profile of the farmer [3].

Agriculture sector is struggling to increase the productivity of crop in India. Monsoon rainfall is the main source of water for more than 60 percent of the crops. Smart agriculture driven by Information Technology is the emerging trend in the research in this area in recent days. One of the areas being explored is the problem of yield prediction which is a major concern. Data mining techniques are being widely used as a part of solution for crop yield prediction. Various data mining techniques are under evaluation for estimation of crop production of the future years [4]. Data mining is the process in which the hidden patterns are discovered using analysis of large data sets. The data mining and data analytics techniques use artificial intelligence, statistics, machine learning and database system. In data mining, unsupervised and supervised methods are being used. In unsupervised learning, clusters are formed using large data sets and in supervised learning classification are done based on the data sets. In clustering technique, 'data points' are examined to group them into 'clusters' according to specific parameter. The data points in same cluster have less distance compared to data points of different clusters. The analysis of the cluster divides data into well organized groups. The natural structure of the data is captured by these well-formed groups [3, 4].

This survey focuses on various methods being used for crop yield prediction. The methods being used are Density based clustering techniques, Multiple Linear regression, Clustering large applications (CLARA), Petitioning around Medoids (PAM) and density based clustering algorithm called DBSCAN.

\section{REVIEW OF LITERATURE METHODS OF CROP YIELD PREDICTION}

At present we are at the immense need of another Green revolution to supply the food demand of growing population. With the decrease of available cultivable land globally and the decreased cultivable water resources, it is almost impossible to report higher crop yield. Agricultural based big data analytics is one approach, believed to have a significant role and positive impact on the increase of crop yield by providing the optimum condition for the plant growth and decreasing the yield gaps and the crop damage and wastage. With this aim the present paper reviews about the various advances, design models, software tools and algorithms applied in the prediction assessment and estimation of the crop yield. India is basically agriculture based country and approximately $70 \%$ our country economics is directly or indirectly related to the agricultural crops. The principle crop which occupies the highest (60-70\%) percentage of cultivable land in the Indian soil is the paddy culture and it is the major crop especially in central and south parts of the India. Rice crop cultivation plays an imperative part in sustenance security of India, contributing over $40 \%$ to general yield generation. The enhanced yield of the rice crop depends largely on the water availability and climatic conditions. For example, low precipitation or temperature extremes can drastically diminish rice yield. Growing better strategies to foresee yield efficiency in a mixture of climatic conditions can help to understand the role of different principle factors that influence the rice crop yield. Big data analytic methods related to the rice crop yield prediction and estimation will certainly support the farmers to understand the optimum condition of the significant factors for the rice crop yield, hence can achieve higher crop yield.

\subsection{Crop Yield Prediction Using Machine Learning}

A research group investigated the utilization of various information mining methods which will foresee rice crop yield for the data collected from the state of Maharashtra, India. A total of 27 regions of Maharashtra were selected for the assessment and the data was collected related to the principle rice crop yield influencing parameters such as different atmospheric conditions and various harvest parameters i.e Precipitation rate, minimum, average, maximum and most extreme temperature, reference trim cultivable area, evapotranspiration, and yield for the season between June to November referred as Kharif, for the years 1998 to 2002 from the open source, Indian Administration records. WEKA a Java based dialect programming for less challenging assistance with information data sets, assigning design outcomes tool was applied for dataset processing and the overall methodology of the study includes, (1) pre-processing of dataset (2) Building the prediction model utilizing WEKA and (3) Analyzing the outcomes. Cross validation study is carried out to scrutinize how a predictable information mining method will execute on an ambiguous dataset. Study applied 10-fold higher cross validation study design to assess the data subsets for screening and testing. Identified and collected information was randomly distributed into 10 sections where in one data section was used for testing while all other data sections were utilized for the preparation information. Study reported that the method applied was supportive in the precise estimation of rice crop yield for the state of 
Maharashtra, India. The precise quantification of the rice productivity in various climatic conditions can help farmer to understand the optimum condition for the higher rice crop yield [8].

Agriculture is one of the major revenue producing sectors of India and a source of survival. Various seasonal, economic and biological factors influence the crop production but unpredictable changes in these factors lead to a great loss to farmers. These risks can be measured when suitable mathematical and statistical model designs are applied on data related to soil, weather and past yield. With the advent of data mining, crop yield can be predicted by deriving useful insights from these agricultural data that aids farmers to decide on the crop they would like to plant for the forthcoming year leading to maximum profit. There are various systems that use diverse data mining technologies to manipulate data to derive insights and help in decision making for farmers. The present data mining systems and algorithms used were focus either on one crop and predict or forecast any one parameter like either yield or price. A research presents a survey on the various algorithms used for crop yield prediction, study used to forecast the yield and price of major crops of Tamil Nadu based on historical data. The data and predicted output are accessible for the farmers through a web application. This aids farmer to decide on the crop they would like to plant for the forthcoming year. In addition, the web application also provides a forum for the farmers to goods the products without middlemen which help them to obtain maximum price for their products [9].

\subsection{Crop Yield Prediction Using Data Mining Techniques}

India is a country where farming and agriculture based industries are the major resource of economy. It is also one of the country which suffer from major natural calamities like drought or flood which damages the crop which cause huge financial loss for the farmers and economic stability of the country. Predicting the crop yield well in advance prior to its harvest can help the farmers and Government organizations to make appropriate planning like storing, selling, fixing minimum support price, importing/exporting etc. Predicting a crop well in advance requires a systematic study of huge data coming from various variables like soil quality, $\mathrm{pH}$, essential elements $(\mathrm{N}, \mathrm{P}, \mathrm{K})$ quantity etc. As Prediction of crop deals with large set of database thus making this prediction system a perfect candidate for application of data mining methodologies which majorly helps in acquiring a knowledge to achieve higher crop yield. The success of any crop yield prediction system heavily relies on how accurately the features have been extracted and how appropriately classifiers have been employed. Study summarizes the results obtained by various algorithms which are being used by various authors for crop yield prediction, with their accuracy and recommendation [10].

Weeds and pests were the major crop damaging biotic agents and the farmers are need to be wellinformed in accessing the various data mining technologies to acquire a knowledge on applications of effective weed and pest control strategies and managing techniques to reduce crop damage. Collection of data related to the various weeds and pest, modeling of the data to prepare for the mining, selection of appropriate methodology, interpretation and sharing the information become the major challenges in weed and pest control to protect the crop damage. A study was conducted to evaluate the major challenges and noteworthy opportunities and applications of of Big Data in controlling the weed and pest damage and hence to achieve higher crop yield. Study reported that the form of the data collected, type of the assessment method and tools applied are the major influencing factors in understanding the role of crop damaging agents such as weed and pest, which provides the knowledge on using improved crop management strategies and crop yield prediction. Big Data cargo space and questioning incurs intense challenges, in respect to allocate the data across numerous technologies, and also continuously evolving data from diverse sources. When the selected data was from the different sources, semantic methodologies play a vital role in the assessment, which preliminarily detect the factors possess potential agricultural importance and developing relationships between data items in terms of meanings and units. Study presented a success story from the Netherlands in using the information from the Big Data analytics, with numerical algorithms in controlling the crop damage and reported the higher crop yield. Study concluded that, the utility and the applications and of Big data analytics for weed and pest control is very large and particularly for invasive, parasitic and herbicide-resistant weeds. Also imported the need of collaboration of agricultural scientists with data scientists to implement the methodologies for the benefit of agricultural practices [6].

Data mining plays a pivotal role for decision making on different concerns with respect to agriculture practices. The objective of the data mining methods is to mine knowledge from an accessible data set and convert it into a comprehensible format for some significant application of the Agri process. Crop management of certain agriculture region is depending on the climatic conditions of that region because climate can make huge impact on crop productivity. Real time weather data can help to achieve the good crop management. Effective utilization of mined agricultural based information and communications expertise enables automation of retrieving useful data in an effort to acquire knowledge, which provides opportunity to easier data acquisition from electronic sources directly, transfer to secure electronic system of 
documentation and reduces manual tasks. Automation strategies reduce the overall production cost, hence support for higher crop yield and higher market price. Also identified that how the data mining helps to analyze and predict the useful pattern from huge and dynamically changed climatic data. In the field of agricultural bioengineering, scientist and engineers in collaboration have developed and discussed the application of mathematical model designs like fuzzy logic designs in optimization of the crop yield, artificial neural networks in validation studies, genetic algorithms designs in accessing the fitness of the model applied, decision trees, as well as support vector machines to assess soil, climate conditions and availability of water resources related to crop growth and pest management in agriculture. Study summarizes the application of data mining technologies i.e Neural Networks, Support Vector Machine, Big Data analysis and soft computing in the assessment of agriculture field based on weather conditions [5].

\subsection{Crop yield prediction using Big Data Analytics}

In India crop yield is season dependent and majorly influenced by the biological and economic causes of an individual crop. Reporting of progressive agricultural yield in all the seasons is an ample task and an advantageous task for every nation with respect to assesses the overall crop yield prediction and estimation. At present a common issue worldwide is, farmers are stressed in producing higher crop yield due to the influence of unpredictable climatic changes and significant reduction of water resource worldwide. A study was carried out to collect the data on world climatic changes and the available water resources which can be used to encourage advanced and novel approaches such as big data analytics to retrieve the information of the previous results to the crop yield prediction and estimation. Study imported that the selection and usage of the most desirable crop according to the existing conditions, support to achieve the higher and enhanced crop yield [11].

The accurate prediction of crop yield certainly benefits the farmers in choosing the right method to reduce the crop damage and gets best prices for their crops. A research group conducted a work with an objective of accurate prediction of crop yield through big data analytics to assess various crop yield influencing factors such as Area under Cultivation (AUC) interims of hectors, Annual Rainfall (AR) rates and Food Price Index (FPI) and to develop relationship among these parameters. Regression Analysis (RA) methodology was applied to examine the selected factors and their impact on crop prediction and final yield. RA methodology is a multivariable investigation practice which can categorize the factors in to groups such as explanatory and response variables and helps to assess their interaction to obtain a resolution. All the selected factors of the present study design known as AR, AUC and FPI were measured for a period of 10 years between the years 1990-2000. A novel method called Linear Regression (LR) is applied to analyze the relationship between explanatory variables (AR, AUC, FPI) and the crop yield considered as response variable. Study reported that the $\mathrm{R}^{2}$ value for the studied factors clearly indicate that crop yield is principally depends on AR. Study also reported that the other two factors (AUC and FPI) screened were also found to have significant impact after the AR. Study shall be continued to analyze the impact of for other substantial factors like Minimum Support Price (MSP), Cost Price Index (CPI), Wholesale Price Index (WPI) etc. and their relationship on the yields of different crops [12].

Crop yield gaps, measured as difference between expected yields based on the potency and actual farm yield received. In order to achieve the higher crop yield, farmers must need to tackle the influencing factors such as influence of change in climate conditions on the prospects of crop yields, and change in the usage of agricultural land to assess and ultimately reduce the crop yield gaps. Several researchers reported the applications of bio simulation models to estimate the crop yield gaps in the last decade. The impact of the crop yield gaps assessment studies conducted through bio simulation based methodologies were negatively influenced by quality and resolution of climate and soil data, as well as unscientifically expectations about crop yield prediction systems and crop yield assessment modeling designs calibration method. An explicit rationale model which can effectively applied at various levels of the availability of quality information for identifying data sources to analyze crop yield and measuring yield gaps at definite geographical locations and works based on the rise in titer approach. The model is highly helpful in retrieving the useful data from the available, poor quality, less rigorous data sources or if the data is not available. A case study was discussed on the application of selected model design to quantify the yield gaps of maize crop in the state of Nebraska (USA), and also at the different geographical locations representing the nations Argentina and Kenya at national scale level. Different geographical locations such as Nebraska (USA), Argentina and Kenya were identified to symbolize the distinct scenarios of Agri based data availability and the quality for the selected variables assessed to predict and estimate the crop yield gaps. The definitive aspiration of the planned method is to afford transparent, easily accessible, reproducible and technically sound and strong guidelines for predicting the yield gaps. The proposed guidelines were also relevant for understanding and to simulate the influence of change in climate conditions and usage of cultivable land changes from national to global scales. As indicated, the better understanding of data importance and usefulness for analyzing crop yield and 
estimating yield gaps as illustrated can help in identifying the data gaps in the crop yield and allow focusing on the various efforts taken at the global level to address the most critical issue [13].

Analyzing the yields of crop is necessary to update the policies to ensure food security. A research group conducted a study with the aim in suggesting a novel data mining method to predict the yields of crop depends on agricultural big data analytics methodologies, which were progressively contrast with conventional data mining methodologies in the process of handling data and modeling designs. Study suggested that the method employed should be user friendly, work based on progressive big-data responsive processing structure, supposed to utilize the existing agricultural based significant datasets and would still be used with the larger volumes of data growing at enormous rates. Nearest neighbors modeling is one such novel data mining technique which works on the results collected based on data processing structures form the farmers and suggest a well unbiased result on the base of accuracy and prediction time in advance. Study further discussed a case study on the assessment of actual crop dataset (numerical examples on) in China from 1995-2014. Study reported that the novel model employed has publicized an improved performance and was found to be progressive in reporting prediction accuracy percentage of the compared methodologies with conventional designs [7].

Simulation models based on field experiment are valuable technologies for studying and understanding crop yield gaps, but one of the critical challenge remain with these methods is scaling up of these approach to assess the data collated between different time intervals from the broader geographical regions. Satellite retrieved data have frequently been revealed to present data sets that, by itself or in grouping with other information and model designs, can precisely determine the yields of crop in agricultural lands. The yield maps developed shall provide an unique opportunity to overcome both spatial and temporal based scaling up challenges and thus improve the ideology of crop yield gaps prediction. A review was conducted to discuss the applications of remote sensing technology to determine the impact and causes of yield gaps. Even though the example discussed by the research group demonstrates the usefulness of remote sensing in the prediction of yield gaps, but also many areas of possible application with respect to the crop yield assessment, prediction and improvement remain unexplored. Study proposed two less complicated, easily assessable methods to determine and quantify the yield gaps between various agricultural fields. First method works closely with the constructive maps representing the average crop yields, it can be used directly to accesses specific crop yield influencing factors for further studies whereas the second method use the remote sensing technology to retrieve the data for providing the useful information regarding the crop yield prediction and estimation [14].

In coming decades, two most significant and important factors found to influence crop yield is, increase in the global population and economy, which greatly demands the higher and sustainable agricultural based crop yields. The capacities of food production at global level is going to be very limited due to the less availability of cultivable land, water resources, difficulties in maintaining the sustainable crop production levels, effects of changes in the global climatic conditions and also by various biophysical parameters which influence the crop yield. The farmers need to be educated on the application of scientifically proven methods to quantify the crop yield capacities and same need to be informed to higher authorities to maintain transparency in sharing the actual information, intern helps in making the policy based, research oriented, development and investment related decisions that aim to influence future crop yield. Crop production abilities and yield gaps can be assessed and measured by comparing the possible yields at normal conditions with respect to the crop production under, respectively, irrigated and rain fed conditions by keeping the crop yield levels limited by the less availability of the water as benchmarks. Yield gaps can be defined as the difference between the expected crop yields with respect to the actual crop yield and accurate, spatially unambiguous awareness and information about the yield gaps is necessary to achieve sustainable amplification of agricultural yields. Keeping an aim of discussing the impact of the various methods practiced in measuring the yield gaps with a spotlight on the local-to-global importance of outcomes, a research group carried out a survey on the various methods applied to estimate yield gaps. Study reported few standard operation methods, employed in quantifying the crop yield potential on the data collected from the farmers of western Kenya, Nebraska (USA) and Victoria (Australia). Study recommended for the use of accurate and recent yield data assessed through calibrated crop model designs and further up scaling validated methods in the prediction of crop yield gaps The bottom-up application of this global protocol allows verification of estimated yield gaps with on-farm data and experiments [15]. 
Table 1. Different data mining techniques applied in crop yield prediction

\begin{tabular}{|c|c|c|c|}
\hline SL & Title of the paper & $\begin{array}{c}\text { Authors / Year of } \\
\text { publication }\end{array}$ & Highlights \\
\hline 1. & $\begin{array}{l}\text { Rice Crop Yield Prediction } \\
\text { using Data Mining } \\
\text { Techniques: An Overview }\end{array}$ & $\begin{array}{l}\text { Dakshayini Patil, } \\
\text { Dr. M .S, Shirdhonkar/ } \\
2017\end{array}$ & $\begin{array}{l}\text { Discussed various data mining techniques utilized for prediction of } \\
\text { rice crop yield for the state of Maharashtra, India. } \\
\text { WEKA tool was applied in dataset processing }\end{array}$ \\
\hline 2. & $\begin{array}{l}\text { A Survey on Crop Yield } \\
\text { Prediction based on } \\
\text { Agricultural Data }\end{array}$ & $\begin{array}{l}\text { Dhivya B H, Manjula R, } \\
\text { Siva Bharathi S, } \\
\text { Madhumathi R/ } 2017\end{array}$ & $\begin{array}{l}\text { Presented a survey on the different algorithms applied in the } \\
\text { assessment and prediction of crop yield } \\
\text { Discussed about the mechanism of knowledge the discovery in } \\
\text { Agricultural data mining }\end{array}$ \\
\hline 3 & $\begin{array}{l}\text { A Study on Various Data } \\
\text { Mining Techniques for } \\
\text { Crop Yield Prediction }\end{array}$ & $\begin{array}{l}\text { Yogesh Gandge, Sandhya/ } \\
2017\end{array}$ & $\begin{array}{l}\text { Discussed various data mining techniques employed for predicting the } \\
\text { crop yield and signifies the importance of accurate data extraction } \\
\text { methods of big data analytics. }\end{array}$ \\
\hline 4. & $\begin{array}{l}\text { Big Data for weed control } \\
\text { and crop protection }\end{array}$ & $\begin{array}{l}\text { F K Van Evert, S Fountas, } \\
\text { D Jakovetic, V Crnojevic, } \\
\text { I Travlos \& C } \\
\text { Kempenaar/ } 2017\end{array}$ & $\begin{array}{l}\text { Critically discussed about the challenges faced and the profound } \\
\text { opportunities lies in the Big Data analytics in agriculture: } \\
\text { Outlined Big Data analytics models with numerical algorithms applied } \\
\text { Represent the importance of reforming the mined data in the form of } \\
\text { understandable information to the farmers. } \\
\text { Discussed about various advances, tools and algorithms applied in } \\
\text { transforming the data in to easily understandable information to the } \\
\text { framers and thrown a light on success story of Netherlands in } \\
\text { achieving the maximum crop yield and their smart forming practices. } \\
\text { Also discussed about the control of invasive, parasitic and herbicide- } \\
\text { resistant weeds to improve the overall crop yield applying Big Data } \\
\text { analytics. }\end{array}$ \\
\hline 5. & $\begin{array}{l}\text { The Impact of Data } \\
\text { Analytics in Crop } \\
\text { Management based on } \\
\text { Weather Conditions }\end{array}$ & Swarupa Rani A/ 2017 & $\begin{array}{l}\text { Discussed the application of mathematical model like fuzzy logic } \\
\text { designs in optimization of the crop yield, artificial neural networks in } \\
\text { validation studies, genetic algorithms designs in accessing the fitness } \\
\text { of the model applied, decision trees, and support vector machines to } \\
\text { study soil, climate conditions and water regimes related to crop growth } \\
\text { and pest management in agriculture. }\end{array}$ \\
\hline 6. & $\begin{array}{l}\text { A Study on Crop Yield } \\
\text { Forecasting Using } \\
\text { Classification Techniques }\end{array}$ & $\begin{array}{l}\text { R.Sujatha, Dr.P.Isakki } \\
\text { Devi/ } 2016\end{array}$ & $\begin{array}{l}\text { Discuss the importance of comparing previous agricultural data with } \\
\text { present to identify optimum condition favor enhanced crop yield. } \\
\text { Envisaged the importance of best crop selection depending onthe } \\
\text { season and the climatic factors which supports enhanced crop yield. }\end{array}$ \\
\hline 7. & $\begin{array}{l}\text { Prediction of Crop Yield } \\
\text { using Regression Analysis }\end{array}$ & $\begin{array}{l}\text { V. Sellamand E. } \\
\text { Poovammal/ } 2016\end{array}$ & $\begin{array}{l}\text { Regression analysis was carried out to find the relationship among the } \\
\text { parameters i.e Area under Cultivation (AUC), Annual Rainfall (AR) } \\
\text { and Food Price Index (FPI) which influences the final crop yield and } \\
\text { reported that the crop yield principally depends on the Annual Rainfall } \\
\text { (AR). }\end{array}$ \\
\hline 8 & $\begin{array}{l}\text { How good is good enough? } \\
\text { Data requirements for } \\
\text { reliable crop } \\
\text { yieldsimulations and yield- } \\
\text { gap analysis }\end{array}$ & $\begin{array}{l}\text { Patricio Grassinia, Lenny } \\
\text { G.J. van Bussel, Justin } \\
\text { Van Warta, Joost } \\
\text { Wolf,Lieven Claessens, } \\
\text { d, Haishun Yanga, } \\
\text { Hendrik Boogaarde, Hugo } \\
\text { de Groote,Martin K. van } \\
\text { Ittersumb, Kenneth G. } \\
\text { Cassman/ } 2015\end{array}$ & $\begin{array}{l}\text { Presented a case study (Nebraska - USA and at a national scale for } \\
\text { Argentina and Kenya) on the application of an explicit rationale design } \\
\text { approach in identifying the data sources which simulates Crop (maize) } \\
\text { yield and also helps in quantifying the maize yield gaps. } \\
\text { Suggested the robust guidelines for analyzing the crop yield gaps, } \\
\text { accessing the climate and land use changes at global level to address } \\
\text { the issues of crop yield. }\end{array}$ \\
\hline 9. & $\begin{array}{l}\text { Prediction of crop yield } \\
\text { using big data }\end{array}$ & $\begin{array}{l}\text { Wu Fan, Chen Chong, } \\
\text { Guo Xiaoling, Yu Hua } \\
\text { Wang Juyun/ } 2015\end{array}$ & $\begin{array}{l}\text { Developed a novel model i.e Nearest neighbors modeling tocalculate } \\
\text { and predict the yield of crop depends on the available Big data sets. }\end{array}$ \\
\hline 10. & $\begin{array}{l}\text { The use of satellite data for } \\
\text { crop yield gap analysis }\end{array}$ & David B. Lobell/ 2013 & $\begin{array}{l}\text { Discussed the use of remote sensing technology to identify and } \\
\text { measure the causes of yield gaps and the assess the impact on the } \\
\text { overall crop yield. } \\
\text { Reported very simple methodologies to measure the yield difference } \\
\text { with respect to season, environment and the land use. }\end{array}$ \\
\hline 11. & $\begin{array}{l}\text { Yield gap analysis with } \\
\text { local to global relevance-A } \\
\text { review }\end{array}$ & $\begin{array}{l}\text { Martin K. van Ittersuma, } \\
\text { Kenneth G. Cassmanb, } \\
\text { Patricio Grassinib, } \\
\text { Joost Wolfa, Pablo } \\
\text { Tittonell, Zvi Hochmand }\end{array}$ & $\begin{array}{l}\text { Discussed about the various methodsused on quantifying the yield } \\
\text { gaps at local-to-global ratio. } \\
\text { Reported few standard operation methods, employed inquantifythe } \\
\text { crop yield potential on the data collected from the farmers ofwestern } \\
\text { Kenya, Nebraska (USA) and Victoria (Australia). } \\
\text { Study recommended for the use of accurate and current yield data, } \\
\text { with calibrated and validated cropmodels and up scaling methods in } \\
\text { the prediction of crop yield. }\end{array}$ \\
\hline
\end{tabular}

\section{CONCLUSION}

As a result of penetration of technology into agriculture field, there is a marginal improvement in the productivity. The innovations have led to new concepts like digital agriculture, smart farming, precision agriculture etc. In the literature, it has been observed that analysis has been done on agriculture soils, hidden patterns discovery using data set related to climatic conditions and crop yields data. The activities of agriculture field are numerous like weather forecasting, soil quality assessment, seeds selection, crop yield 
prediction etc. In this survey, the specific activity, crop yield prediction has been surveyed and the major trends have been identified.

The rice crop yield prediction has been done in the state of Maharashtra using data mining techniques in one of the works [8]. The analysis has been done using machine learning framework WEKA. In the work carried out in [9], various algorithms applied in the assessment crop yield and mechanism for knowledge discovery has been discussed. The challenges and opportunities in the field of Big Data analytics in agriculture has been discussed in [6] with a case study of Netherlands. Fuzzy logic designs have been used in optimizing the crop yields and the same has been explained in the research work in [5]. A case study of Nebraska - USA and at a national scale for Argentina and Kenya has been done and presented in [14]. The remote sensing technology for identification and measurement of the causes of yield gaps and their impact on final crop yield is presented in [15].

It can be concluded that the research in the field of agriculture with reference to using IT trends like data analytics is in its infancy. As the food is the basic need of humans, the requirement of getting the maximum yields using optimal resource will become the necessity in near future as a result of growing population. The survey outcomes indicate the need for improved techniques in crop yield analytics. There exists a lot of research scope in this research area.

\section{REFERENCES}

[1] Dhivya B H, Manjula R, Siva Bharathi S, Madhumathi R. A Survey on Crop Yield Prediction based on Agricultural Data, International Journal of Innovative Research in Science, Engineering and Technology. 2017; 6(3).

[2] Jharna Majumdar, Sneha Naraseeyappa, Shilpa Ankalaki. Analysis of agriculture data using datamining techniques: application of big data. Journal of Big data. 2017.

[3] Majumdar J, Ankalaki S. Comparison of clustering algorithms using quality metrics with invariant features extracted from plant leaves. International Conference on Computational Science and Engineering. 2016.

[4] D Ramesh, B Vishnu Vardhan. Data Mining Techniques and Applications to Agricultural Yield Data. International Journal of Advanced Research in Computer and Communication Engineering. 2013; 2(9).

[5] Swarupa Rani. The Impact of Data Analytics in Crop Management based on Weather Conditions. International Journal of Engineering Technology Science and Research. 2017; 4(5):299-308.

[6] F K Van Evert, S Fountas, D Jakovetic, V Crnojevic, I Travlos, C Kempenaar. Big Data for weed control and crop protection. John Wiley \& Sons Ltd on behalf of European Weed Research Society, 2017: 218-233.

[7] Wu Fan, Chen Chong, Guo Xiaoling, Yu Hua. Prediction of crop yield using Big Data. 8th International Symposium on Computational Intelligence and Design. 2015.

[8] Dakshayini Patil, M .S, Shirdhonkar. Rice Crop Yield Prediction using Data Mining Techniques: An Overview. International Journal of Advanced Research in Computer Science and Software Engineering, 2017; 7(5):427-431.

[9] Dhivya B H, Manjula R, Siva Bharathi S, Madhumathi R. A Survey on Crop Yield Prediction based on Agricultural Data, International Journal of Innovative Research in Science, Engineering and Technology. 2017; 6(3):4177-4182.

[10] Yogesh Gandge, Sandhya. A Study on Various Data Mining Techniques for Crop Yield Prediction, International Conference on Electrical, Electronics, Communication, Computer and Optimization Techniques, IEEE, 2017;420423

[11] R. Sujatha, P.Isakki Devi. A Study on Crop Yield Forecasting Using Classification Techniques, IEEE, 2016.

[12] V. Sellam and E. Poovammal. Prediction of Crop Yield using Regression Analysis, Indian Journal of Science and Technology, 2016; 9(38).

[13] Patricio Grassinia, Lenny G.J. van Bussel, Justin Van Warta, Joost Wolf, Lieven Claessens, d, Haishun Yanga, Hendrik Boogaarde, Hugo de Groote, Martin K. van Ittersumb, Kenneth G. Cassman. How good is good enough? Data requirements for reliable crop yield simulations and yield-gap analysis. Field Crops Research. 2015; 49-63.

[14] David B. Lobell, The use of satellite data for crop yield gap analysis, Field Crops Research-143, 2013; 56-64.

[15] Martin K. van Ittersuma, Kenneth G. Cassmanb, Patricio Grassinib, Joost Wolfa, Pablo Tittonell, Zvi Hochmand. Yield gap analysis with local to global relevance-A review. Field Crops Research - 143, 2013; 4-17 